\title{
Fibre Bragg grating based effective soil pressure sensor for geotechnical applications
}

\author{
Ricardo Correia ${ }^{1}$, Jin $\mathrm{Li}^{1}$, Stephen Staines ${ }^{1}$, Edmon Chehura ${ }^{1}$, Stephen W. James ${ }^{1}$, Joel Kutner ${ }^{2}$, Paul \\ Dewhurst $^{2}$, Pedro Ferreira ${ }^{2}$ and Ralph P. Tatam ${ }^{1 *}$ \\ ${ }^{1)}$ Engineering Photonics Group, School of Engineering, Cranfield University, Cranfield, UK, \\ ${ }^{2)}$ Soil Mechanics Group, Department of Civil, Environment and Geomatic Engineering, University \\ College of London, London, UK
}

\begin{abstract}
An effective-soil-pressure sensor for geotechnical applications based on Fibre Bragg Gratings is presented. The sensor simultaneous measures total soil pressure and pore pressure, allowing the calculation of the effective stress of soil. Calibration of the sensor using pressurised air demonstrated a pressure sensitivity of $2.02 \times 10^{-3} \pm 2.84 \times 10^{-5} \mathrm{~nm} / \mathrm{kPa}$ and $1.87 \times 10^{-3} \pm 6.88 \times 10^{-5} \mathrm{~nm} / \mathrm{kPa}$ for the total and pore pressure respectively. This corresponds to a pressure resolution of $4.95 \times 10^{-1} \mathrm{kPa}$ and $5.46 \times 10^{-1} \mathrm{kPa}$ for total and pore pressure using a $1 \mathrm{pm}$ interrogation system. Measurements undertaken in two types of soil demonstrated dependence of the total pressure sensitivity on soil density/stiffness. Pore pressure measurements agreed well with the preliminary calibration.
\end{abstract}

Keyword List: Total soil pressure, Pore pressure, Effective soil stress, Fibre Bragg Grating.

\section{INTRODUCTION}

Human infrastructure is built on soils and therefore a good understanding of the mechanics of soil systems is required to assess their stability. In a saturated soil where no water movement exists, the total pressure in the soil at a certain depth is result of the sum of the effective soil stress and pore water pressure. Effective soil stress is related to the internal forces acting on the contact points of the particles, while the stress within the liquid phase (water) is called pore pressure. In geotechnical engineering and soil sciences, acknowledgement of the effective soil pressure is of extreme importance.

Electrical and fibre optic based total soil pressure and pore pressure sensors are commercially available. The electrical sensors use technologies such as vibrating wire or electrical strain gauges but their long term stability and durability present drawbacks which may be overcome by the use of fibre optic based sensors. Electrical sensors lack the multiplexing capability of fibre optic technology. The available fibre optic sensors are mainly based on interferometric or Fibre Bragg Grating (FBG) technologies ${ }^{1,2}$. FBG based sensors are preferred to interferometric systems due to the ease of multiplexing. Many types of FBG based pressure sensors have been reported in the literature. The intrinsic pressure sensitivity of optical fibres is relatively low and a number of different techniques have been developed to increase the pressure sensitivity of FBGs by means of mechanical or other packaging techniques that transduce pressure into an axial strain across the FBG length ${ }^{3,4,5}$. The simplest way to transduce soil pressure into a measurable signal from an FBG is to attach the FBG to a thin plate and monitor the wavelength shift of the Bragg peak in response to the deflection of the plate as a function of the applied pressure ${ }^{6}$. This technique has been applied to develop a pressure sensor capable of measuring soil total pressure ${ }^{7}$. The limitation of this sensor is that it can only be used in unsaturated soils where no pore pressure exists and therefore the effective soil pressure is equal the total soil pressure. Extension of the use of this sensor on a saturated soil would require an additional pore pressure sensor to be used. In this paper we present an FBG based effective soil pressure sensor capable of performing the simultaneous measurement of soil total pressure and pore pressure allowing the measurement of the effective stress of the soil at a certain depth.

\section{SENSING PRINCIPLE}

The effective pressure sensor developed uses two diaphragms as sensing elements which independently transfer the soil total pressure and pore pressure into an axial strain along an FBG. A schematic diagram of the pressure sensor is

${ }^{*}$ Contact author

20th International Conference on Optical Fibre Sensors, edited by Julian Jones, Brian Culshaw, Wolfgang Ecke, José Miguel López-Higuera, Reinhardt Willsch, Proc. of SPIE Vol. 7503, 75030F (c) 2009 SPIE $\cdot$ CCC code: $0277-786 X / 09 / \$ 18 \cdot$ doi: $10.1117 / 12.835751$

Proc. of SPIE Vol. 7503 75030F-1 
presented in Figure 1-a. The total soil pressure (effective stress + pore pressure) exerts a direct load over diaphragm (A) while only pore pressure acts on diaphragm (B) due to a porous sintered stainless steel filter attached to the sensor.

According to thin plate theory ${ }^{8}$, the amount of deflection $w$ obtained by an applied pressure $P$ at a certain radial distance $r$ from the centre of a plate of radius $a$ clamped at the edges is:

$$
w=\frac{3 p\left(1-v^{2}\right)}{16 E h^{3}}\left(a^{2}-r^{2}\right)^{2}
$$

where $E$ is Young's modulus of the plate material, $v$ is Poisson's ratio and $h$ is the thickness of the circular plate. According to Hooke's law, and assuming that no rotation of the plate is allowed due to the edge clamping, the strain in the radial direction is given by ${ }^{8}$ :

$$
\varepsilon_{r r}=\frac{3 p\left(1-v^{2}\right)}{8 E h^{2}}\left(a^{2}-3 r^{2}\right)
$$

The strain obtained is maximum at the centre of the plate where $r=0$ and zero for $r=\mathrm{a} / \sqrt{3}$ and therefore the FBG was attached to the centre of the diaphragm to maximise the strain transfer. Compensation of thermally induced wavelength shifts could be undertaken by placing a second FBG on one of the diaphragms at the neutral position, i.e. at $r=\mathrm{a} / \sqrt{ } 3$, resulting in a broadening of the FBG reflection peak with the pressure increase while the wavelength position of the Bragg envelop would be only sensitive to temperature ${ }^{6}$.

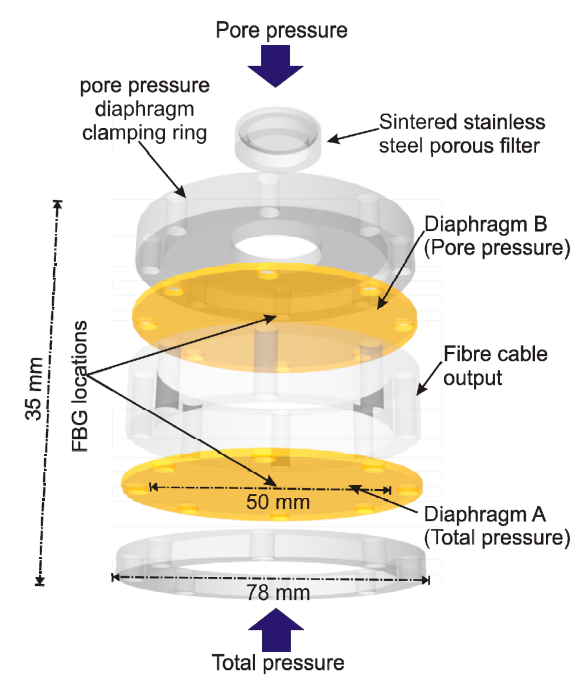

(a)

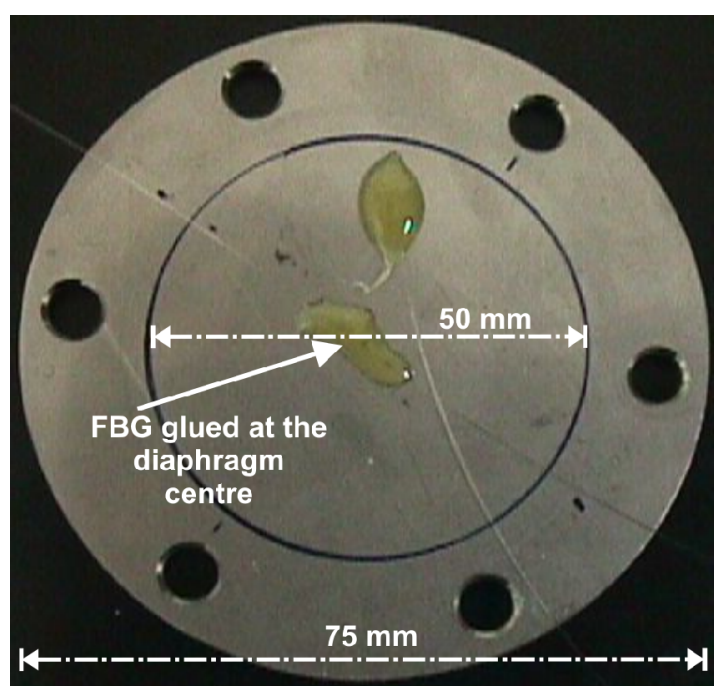

(b)

Figure 1: (a): Schematic diagram of the effective pressure sensor and (b): Photograph of an FBG glued at the diaphragm centre.

\section{SENSOR CALIBRATION}

Two 4-mm long FBGs, fabricated in-house, with central wavelengths of $1555.25 \mathrm{~nm}$ and $1556.11 \mathrm{~nm}$ and reflectivity of $20 \%$ were attached to the centre of two $50 \mathrm{~mm}$ diameter and $1 \mathrm{~mm}$ thick diaphragms using a two component epoxy resin. The thin plates were made of 316 grade stainless steel which has a Young's modulus and Poisson's ratio of 193 $\mathrm{GPa}$ and 0.3 respectively. The FBGs were interrogated using a tunable laser (Tunics) with a $1 \mathrm{pm}$ resolution and the reflected light from the FBGs was coupled to a detector. Each diaphragm was calibrated by attaching the diaphragm to the pore pressure diaphragm clamping ring (Figure 1-a) and replacing the sintered stainless steel filter by an air plug that direct connected to a $1 \mathrm{kPa}$ resolution Druck calibrator. Figure 2 presents the results of the pressure calibration of both thin plates.

A total pressure in the range of 0 to $1000 \mathrm{kPa}$ at $100 \mathrm{kPa}$ increments was applied to both diaphragms and the dependence of the Bragg wavelength on the applied pressure exhibited good linearity. A pressure sensitivity of $2.02 \times 10^{-3} \pm 2.84 \times 10^{-5}$ $\mathrm{nm} / \mathrm{kPa}$ and $1.87 \times 10^{-3} \pm 6.88 \times 10^{-5} \mathrm{~nm} / \mathrm{kPa}$ was obtained for the total and pore pressure diaphragms respectively. The difference in sensitivities obtained is attributed to a mismatch in the placement of the FBG in the centre of the diaphragms. The pressure resolution of the sensors when interrogated with a $1 \mathrm{pm}$ interrogation system is $4.95 \times 10^{-1} \mathrm{kPa}$ and $5.46 \times 10^{-1} \mathrm{kPa}$ for the total and pore pressure diaphragms respectively. 


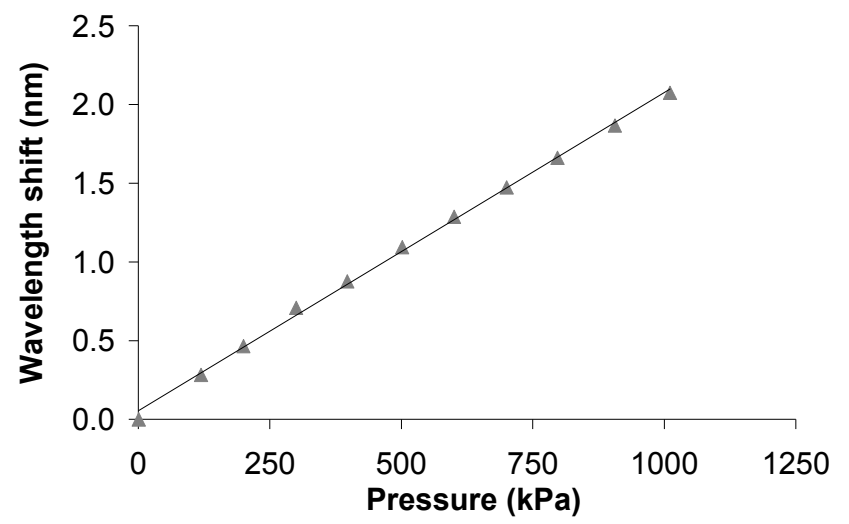

(a)

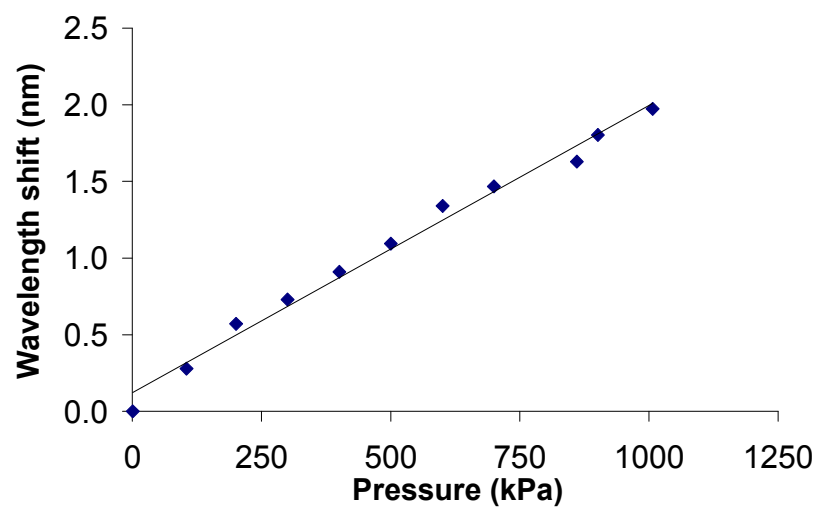

(b)

Figure 2: (a) Dependence of the Bragg wavelength on the pressure applied to the total pressure diaphragm and (b) pore pressure diaphragm.

Following the sensor calibration, the measurement of the total pressure and pore water pressure was undertaken in two different soil types. For this experiment the Rowe cell presented in Figure 3 was used. Vertical stress is applied to the soil by means of an air pressure system that inflates a rubber membrane placed on the top of the soil. Pore pressure is increased by a water pressure system that is connected to a porous filter located at the bottom of the chamber where soil is placed. Fine sand consisting of 212 to $425 \mu \mathrm{m}$ diameter soil particles and coarse sand composed of 0.6 to $1 \mathrm{~mm}$ diameter soil particles were independently tested. The effective pressure sensor was placed within the soil, at a depth of $50 \mathrm{~mm}$ and both the total and pore pressures were applied to the Rowe cell using two independent pressurising systems. Total pressure was measured over a range of up to $800 \mathrm{kPa}$ at $100 \mathrm{kPa}$ increments and pore pressure was increased up to $500 \mathrm{kPa}$ in $100 \mathrm{kPa}$ increments. The results obtained are presented in Figure 4.

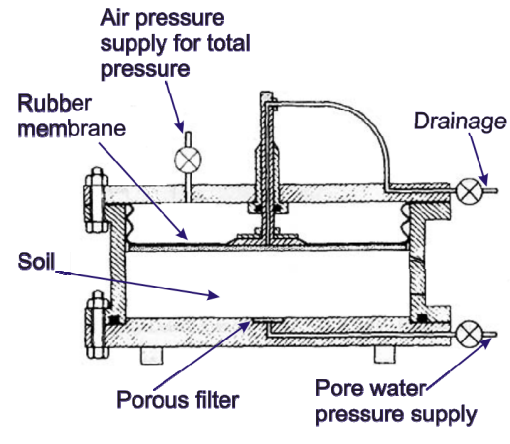

(a)

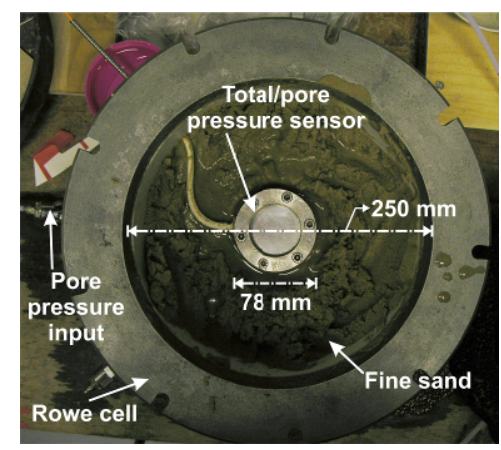

(b)

Figure 3 (a) Diagram of the Rowe cell; (b) photograph of the sensor installation.

In Figure 4 (a) it is observed that the soil total pressure measured at the sensor location is 4 times smaller than the total pressure applied to the soil for coarse sand and is 1.8 times smaller for the fine sand. This amounts to a sensitivity close to $25 \%$ of the sensitivity obtained with the air calibration for coarse sand, and $43 \%$ for fine sand. The difference in sensitivities when compared with the calibration undertaken using pressurised air is attributed to the different soil densities/stiffness that influences the interaction of the soil with the diaphragm, resulting in different soil arching conditions $^{9,10}$. Soil arching results from the deflection of the diaphragm that induces a disturbance of the stress field adjacent to the boundary, leading to a reduction of the actual pressure applied to the sensor ${ }^{9}$. The more accentuated sensitivity reduction obtained for coarse sand is a result of a higher soil stiffness compared with the fine sand, and presents behaviour similar to that observed by Talesnick ${ }^{9}$. To reduce the soil arching effect, a diaphragm with higher stiffness would be required to match the stiffness of the soil. When developing a soil pressure sensor it is desirable to perform a calibration of the sensor with different types of soil in order to obtain the calibration factor for that soil. 


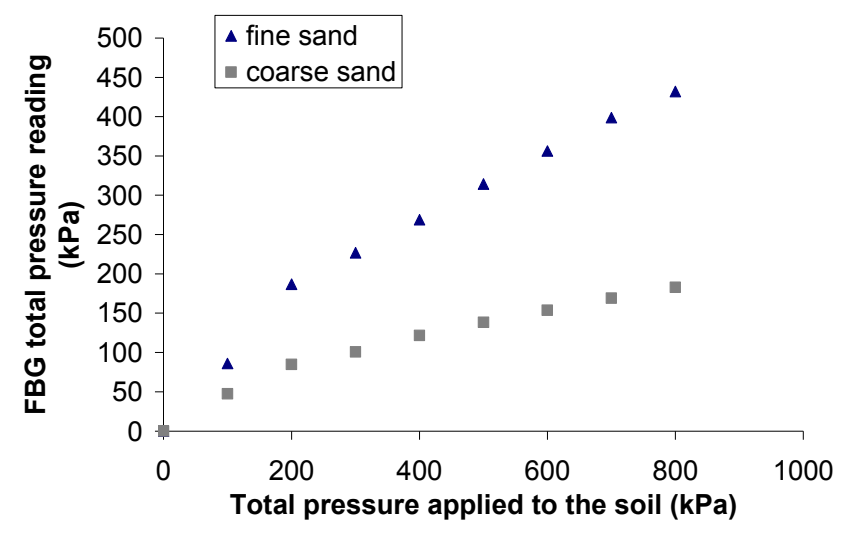

(a)

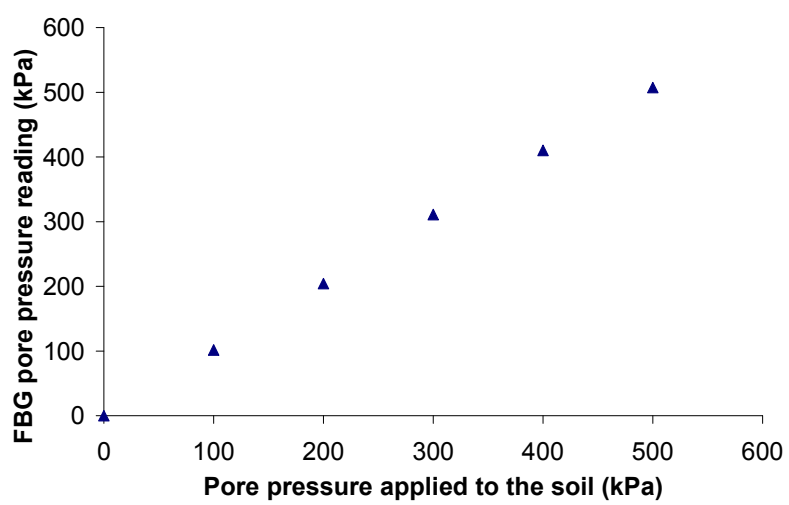

(b)

Figure 4: Effective pressure sensor reading for: (a) Soil total pressure of fine and coarse sand; (b) Pore pressure

The pore pressure reading of the sensor showed good agreement with the pore pressure applied to the Rowe cell. In contrast with the total pressure, the pore pressure readings showed better agreement with the air calibration results as water, similarly to air, applies a uniform load across the diaphragm.

\section{CONCLUSION}

An effective soil pressure sensor that allows the independent measurement of total pressure applied to soil and pore pressure was developed. Calibration of the sensor with air and different types of soil demonstrated that the response of the total pressure sensor is dependent on the soil type, exhibiting different sensitivities to the applied load for the different types of soil. For the pore pressure measurement it was observed that identical readings were obtained with the sensor when calibrated with air and measuring pore pressure.

\section{ACKNOWLEDGMENTS}

The authors gratefully acknowledge the support of the Engineering and Physical Sciences Research Council UK for funding under grant EP/D506654/1.

\section{REFERENCES}

[1] Cappa, F., Guglielmi, Y., Gaffet, S., Lançon, H. and Lamarque, I., "Use of in situ fiber optic sensors to characterize highly heterogeneous elastic displacement fields in fractured rocks", I. Rock Mech. And Min. Sci., 43(4), 647-654, 2006

[2] Guidelines for Instrumentation and Measurements for Monitoring Dam Performance, ASCE, 712 p., 2000

[3] Xu, M., Geiger, H. and Dakin, J., “Optical in-fibre grating high pressure sensor”, Elect. Letters, 29, 398-399, 1993

[4] Maier, R., Barton, J. Jones, J, McCulloch, S and Burnell, G. "Dual fibre Bragg grating sensor for barometric pressure measurement”, Meas. Sci. Technol., 14, 2015-2020, 2003

[5] Correia, R. Chehura, E., James, S. and Tatam, R., "A pressure sensor based upon the transverse loading of a subsection of an optical fibre Bragg grating” Meas. Sci. Technol., 18, 3103-3110, 2007

[6] Ho, Y., Huang, A. and Lee, J. "Development of a chirped/differential optical fiber Bragg grating pressure sensor", Meas. Sci. Technol., 19, 1-6, 2008

[7] Zhou, Z., Wang, H. and Ou, J. "A New Kind of FBG-based Soil-Pressure Sensor", Optical Fiber Sensors, OSA Technical Digest (CD), paper ThE90, Optical Society of America, Cancun, 2006

[8] Reddy, J. N. "Theory and analysis of elastic plates" 2nd Edition, 547 p., Taylor \& Francis, London, 1999.

[9] Talesnick, M. "Measuring Soil Contact Pressure on a Solid Boundary and Quantifying Soil Arching", Geotechnical Testing Journal, 28(2), 1-9, 2005

[10] Tory, A. and Sparrow, R., "The influence of diaphragm flexibility on the performance of an earth pressure cell", Journal of Sci. Inst., 44, 781-785, 1967 